\title{
The Role of the Pharmacist in Pre-Exposure Prophylaxis
}

\author{
Celia Moffat Joel Matyanga \\ Pharmaceutical Technology Department, Harare Institute of Technology, Harare, Zimbabwe \\ Email: celiammj@yahoo.com
}

Received 5 December 2013; revised 6 February 2014; accepted 26 February 2014

Copyright (C) 2014 by author and Scientific Research Publishing Inc.

This work is licensed under the Creative Commons Attribution International License (CC BY). http://creativecommons.org/licenses/by/4.0/

(c) (i) Open Access

\begin{abstract}
Pre-exposure prophylaxis is a new HIV prevention method that has shown to be effective in HIV uninfected persons at very high risk of HIV infection. It involves daily use of truvada in combination with other proven methods of HIV prevention. The aim of this paper is to discuss the various roles that pharmacists play in pre-exposure prophylaxis to maximize therapy.
\end{abstract}

\section{Keywords}

HIV; PrEP; Role; Pharmacist

\section{Introduction}

Pre-exposure prophylaxis is an approach to preventing HIV acquisition and involves the regular use of antiretroviral (ARV) medicines by HIV uninfected individuals as a method to reduce their risk of new HIV acquisition [1]. The idea of pre-exposure prophylaxis (PrEP) emanated from the use of ARVs in preventing HIV infection, such as in prevention of mother-to-child transmission (PMTCT) and post-exposure prophylaxis (PEP.) PrEP has been shown to be effective in prior clinical trials [2]-[5]. The efficacy of ARVs in HIV prevention led the Food and Drug Administration (FDA) to license truvada (200 mg of emtricitabine plus $300 \mathrm{mg}$ of tenofovir disoproxil fumarate) as the first ever drug to prevent Human Immunodeficiency Virus (HIV) infection in adults. Truvada was licensed to be taken once daily and to be used in combination with safer sex practices to reduce the risk of sexually acquired HIV infection in adults who do not have HIV, but are at high risk of becoming infected [6]. Use of PrEP may benefit vulnerable women at high risk for HIV, sero-discordant couples, men who have sex with men (MSM) and injectable drug users (IDUs.)

Pharmacies may be the first point of calling for patients' enquiry about PrEP since there are no consultation fees involved. Thus pharmacists should be aware of their roles in pre-exposure prophylaxis for HIV prevention. 


\section{The Roles of the Pharmacist in Pre-Exposure Prophylaxis}

\subsection{Medication Adherence Counselling and Monitoring}

All the clinical trials on PrEP universally showed that patients with high levels of drug adherence had more protection against HIV-1 [2]-[5]. Some PrEP clinical trials were discontinued early due to futility, and low adherence was cited as the major cause of futility [7] [8]. Thus in order for PrEP to be successful, there is need for high levels of adherence. Pharmacists can improve adherence marginally using the various tools and strategies [9]. These strategies include use of pill boxes, alarms, cell phones, diaries, incident reminders, role of peers/ family members etc. Pharmacists can also educate patients on how PrEP works and the importance of having sufficient drug plasma concentrations to be protected against HIV. Through direct interaction with the patient, pharmacists can also identify barriers to adherence and find ways to assist patients. Since truvada is included in the first line treatment of HIV [10], there is a possibility of sharing amongst those using it as treatment for HIV and those using it for PrEP. The possible dangers of sharing medications include development of drug resistance or even treatment failure for the one who lends [11]. Pharmacists can also discuss the dangers of sharing or borrowing medications amongst patients.

\subsection{Monitoring Adverse Effects}

The results of the successful PrEP clinical trials were indicative that vomiting, nausea and dizziness occurred more frequently among participants who received Truvada than among those who received placebo. However, these symptoms lessened after the first month [2]-[5]. Depending on severity, such symptoms may discourage patients from continuing with medication. These symptoms can be managed in the pharmacy, even with nonpharmacological therapy. Use of tenofovir has been associated with decrease in bone mineral density [12]. Pharmacists can counsel patients on ways to prevent osteoporosis and increase bone density. The package insert for truvada carries a black box warning that lactic acidosis and severe hepatomegaly with steatosis have been reported with the use of tenofovir/emtricitabine [12]. Signs of lactic acidosis are nonspecific and may include nausea, vomiting, diarrhoea, somnolence, epigastric pain, anorexia, tachypnea and lethargy. The pharmacist can be wary of these signs and counsel patients accordingly.

\subsection{Detection of Drug-Drug Interactions}

Truvada for pre-exposure prophylaxis should not be used in patients with unknown or positive HIV-1 infection. Co-administration of truvada with other products containing emtricitabine or tenofovir is also contraindicated. Such products include Atripla (tenofovir disoproxil fumarate, emtricitabine, efavirenz), Complera (emtricitabine, rilpivirine, tenofovir disoproxil fumarate), Emtriva (emtricitabine) and Viread (tenofovir disoproxil fumarate.) Due to the nephrotoxic nature of truvada, it should not be administered in combination with other nephrotoxic drugs like aminoglycosides, non-steroidal anti-inflammatory drugs, $\beta$ lactam antibiotics, diuretics, statins etc. With this knowledge, pharmacists are better equipped than most health professionals to avoid drug interactions that may endanger patients on PrEP.

\subsection{Acquisition of Drugs}

With the recent advances of technology, internet pharmacies are now widespread and medicines can be purchased even without a prescription [11]. Before patients can use PrEP, they should be assessed as being at very high risk for HIV acquisition [13]. Pharmacists should discourage patients from acquiring medicines over the internet. Patients on PrEP need to be monitored for adverse effects, laboratory values and especially for medication adherence [14]. Whilst some of the internet pharmacies are legit, some of them are of disreputable sources. The pharmacist should counsel patients against purchasing medicines from such sources and explain the danger of buying counterfeit drugs.

\subsection{Patient Education}

The recommendation by FDA for using PrEP states that truvada should be used together with other HIV prevention strategies [6]. Pharmacists can play a key role in educating patients on the use of traditional methods of HIV prevention. Some of the methods include sexual abstinence, having and being faithful to one sexual partner, 
correct and consistent use of male/female condoms, screening and early treatment of sexually transmitted infections (STIs), preventing injection-related transmission, male circumcision, PMTCT and PEP [15]. Hence pharmacists can advise patients to use these methods in addition to PrEP. In addition, pharmacists can encourage patients to seek voluntary counselling and testing services for HIV. Pharmacies can be places where the public is free to access friendly and supportive counselling services regarding HIV/AIDS, STIs, hepatitis and tuberculosis. Educating the public could help in reducing stigma associated with these diseases.

\section{Conclusion}

Pharmacists' involvement has proven to be beneficial in numerous disease states. The role of the pharmacist has been pivotal in reducing cardiovascular risk factors like cholesterol, smoking and blood pressure [16]. Thus pharmacists also have a role to play in pre-exposure prophylaxis. Medication knowledge, adherence counselling, and adverse effect monitoring are the pillar of successfully using PrEP and these requirements all fall under the role of the pharmacist. Together with other clinicians, pharmacists should be involved in the use of PrEP for it to prevent acquisition of HIV.

\section{Acknowledgements}

Much love to Brian, Unathi and Theo for your support and patience. Sophie, thank you for instilling the passion for excelling. To the four daughters of Moffat, Wendy and Mimi I can never thank you enough.

\section{References}

[1] Cohen, M.S. and Baden, L.R. (2012) Pre-exposure Prophylaxis for HIV-Where Do We Go from Here? New England Journal of Medicine, 367, 5. http://dx.doi.org/10.1056/NEJMe1207438

[2] Thigpen, C.M., Kebaabetswe, P.M., Paxton, L.A., Smith, D.K., Rose, C.E., Segolodi, T.M., et al. (2012) Antiretroviral Pre-Exposure Prophylaxis for Heterosexual HIV Transmission in Botswana. New England Journal of Medicine, 367, 423-434. http://dx.doi.org/10.1056/NEJMoa1110711

[3] Baeten, J.M., Donnell, D., Ndase, P., Mugo, N.R., Campbell, J.D., Wangisi, J., et al. (2012) Antiretroviral Prophylaxis for HIV Prevention in Heterosexual Men and Women. New England Journal of Medicine, 367, 399-410. http://dx.doi.org/10.1056/NEJMoa1108524

[4] Grant, R.M., Lama, J.R., Anderson, P.L., McMahan, V., Liu, A.Y., Vargas, L., et al. (2010) Pre-Exposure Chemoprophylaxis for HIV Prevention in Men Who Have Sex with Men. New England Journal of Medicine, 363, 2587-2599. http://dx.doi.org/10.1056/NEJMoa1011205

[5] Choopanya, K., Martin, M., Suntharasamai, P., Sangkum, U., Mock, P.A., Leethochawalit, M., et al. (2013) Antiretroviral Prophylaxis for HIV Infection in Injecting Drug Users in Bangkok, Thailand (The Bangkok Tenofovir Study): A Randomised, Double-Blind, Placebo-Controlled Phase 3 Trial. Lancet, 381, 2083-2090. http://dx.doi.org/10.1016/S0140-6736(13)61127-7

[6] FDA Approves First Medication to Reduce HIV Risk. http://www.fda.gov/downloads/ForConsumers/ConsumerUpdates/UCM311828.pdf

[7] Van Damme, L., Corneli, A., Ahmed, K., Agot, K., Lombaard, J., Kapiga, S., et al. (2012) Pre-Exposure Prophylaxis for HIV Infection among African Women. New England Journal of Medicine, 367, 411-422. http://dx.doi.org/10.1056/NEJMoa1202614

[8] Press Release. Daily HIV Prevention Approaches Didn’t Work for African Women in the VOICE Study. http://www.avac.org/ht/a/GetDocumentAction/i/49174

[9] Nichols-English, G. and Poirier, S. (2000) Optimizing Adherence to Pharmaceutical Care Plans. Journal of the American Pharmaceutical Association, 40, 475-485.

[10] (2013) Consolidated Guidelines on the Use of Antiretroviral Drugs for Treating and Preventing HIV Infection. Recommendations for a Public Health Approach. http://apps.who.int/iris/bitstream/10665/85321/1/9789241505727_eng.pdf

[11] Clauson, K.A., Polen, H.H., Joseph, S.A. and Zapantis, A. (2009) Role of the Pharmacist in Pre-Exposure Chemoprophylaxis (PrEP) Therapy for HIV Prevention. Pharmacy Practice (Internet), 7, 11-18. http://dx.doi.org/10.4321/S1886-36552009000100002

[12] (2012) Investigator’s Brochure: Truvada ${ }^{\circledR}$ (Emtricitabine/Tenofovir Disoproxil Fumarate) Tablets. Gilead Sciences, Foster City. 
[13] CDC (2011) Characteristics Associated with HIV Infection among Heterosexuals in Urban Areas with High AIDS Prevalence-24 Cities, United States, 2006-2007. MMWR, 60, 1045-1049.

[14] (2012) Interim Guidance for Clinicians Considering the Use of Preexposure Prophylaxis for the Prevention of HIV Infection in Heterosexually Active Adults. MMWR, 61, 586-589.

[15] (2013) Proven HIV Methods. Centers for Disease Control and Prevention. http://www.cdc.gov/nchhstp/newsroom/docs/HIVFactSheets/Methods-508.pdf

[16] Santschi, V., Chiolero, A., Burnand, B., Colosimo, A.L. and Paradis, G. (2011) Impact of Pharmacist Care in the Management of Cardiovascular Disease Risk Factors: A Systematic Review and Meta-Analysis of Randomized Trials. Archives of Internal Medicine, 171, 1441-1453. http://dx.doi.org/10.1001/archinternmed.2011.399 